\title{
LITHIUM-RICH CLASSICAL CEPHEID V1033 CYG: EVOLUTIONARY STATUS
}

\author{
S. N. Udovichenko, V. V. Kovtyukh and L. E. Keir \\ Astronomical Observatory, Odessa National University, \\ Odessa, Ukraine, udovich222@ukr.net
}

\begin{abstract}
We investigate evolutional status of cepheid V1033 Cyg in this work, its period of light variation consists $4^{d} .94$ and the star is a real candidate on first crossing of instability stripe (IS) (as well as $\alpha$ of UMi). At first crossing of instability stripe, that lasts all close 1000 years, cepheids demonstrate the rapid increase of period, sometimes is a presence of strong line of lithium $6707 \AA$. Such objects knows only four in our Galaxy, one of them - V1033 Cyg. During included in a instability stripe amplitude of pulsations headily grows from a zero to some permanent size, and on leaving from (IS) - again falls to a zero. For verification this phenomenon in the Astronomical observatory of Odesa National University (Ukraine) on the 48-cm telescope AZT-3, equipped by CCD photometer with the optical sensor Sony ICX429ALL, a 1864 measuring of light V1033 Cyg were done in the filter of V and 713 in the filter $\mathrm{R}$, that are partly presented in the Table. 1 and Fig. 2, and fully accessible to address http://cdsarc.ustrasbg.fr/viz-bin/cat. Considerable change of amplitude it is not got by us. The position of cepheid is certain by us in the (IS) - it appeared that star is near her center. In this phase evolutional to development and it must not be observed considerable change of amplitude (color index). The light curves, effective temperature and luminosity of V1033 Cyg are consistent with fundamental mode pulsation for a classical Cepheid on the center of the instability strip.
\end{abstract}

АНОТАЦЯЯ. У даній роботі ми досліджуємо еволюційний статус цефеїди V1033 Суg, період зміни блиску якої становить $4^{d} .94$, і яка є реальним кандидатом на перше перетинання смуги нестабільності (як і $\alpha \mathrm{UMi}$ ). При першому перетину смуги нестабільності $(\mathrm{CH})$, який триває всього близько 1000 років, цефеїди демонструють швидке зростання періоду, інколи - наявність сильної лінії літія $6707 \AA$. Таких об'єктів відомо лише 4 у нашій Галактиці, одна з них - V1033 Суg. Під час входу у смугу нестабільності амплітуда пульсацій стрімко зростає від нуля до якоїсь сталої величини, а при виході зі $\mathrm{CH}$ - знову падає до нуля. Для перевірки цього явища в Астрономічній обсерваторії Одеського національного університету (Україна) на 48-см телескопі АЗТ-3, оснащеному фотометром 3 ПЗ3-матрицею Sony ICX429ALL, були зроблені 1864 вимірювання блиску V1033 Суg в фільтрі V, i 713 вимірювань у фільтрі R, які частково наведені в табл. 1 та на рис. 2, а повністю доступні за адресою http://cdsarc.ustrasbg.fr/vizbin/cat. Значної зміни амплітуди нами не отримано. Нами визначено положення цефеїди у смузі нестабільності - виявилося що вона знаходиться біля ㄲï центру. У цій фазі еволюційного розвитку і не повинно спостерігатися значної зміни амплітуди (показників кольору). Криві блиску, ефективна температура і світність V1033 Суg відповідають стадії фундаментальних пульсацій класичних цефеїд у центрі смуги нестабільності.

Keywords: Stars: variables: Cepheids - V1033 Cyg

\section{Introduction}

V1033 Cyg (GSC 2674.03107), $\left(\alpha_{J 2000.0}=\right.$ $\left.20^{h} 05^{m} 20.66^{s} ; \delta_{J 2000.0}=+32^{\circ} 39^{\prime} 32.5^{\prime \prime}\right)$ is the classical cepheid variable star (GCVS) with amplitude $14 .^{m} 4-15 .^{m} .5(\mathrm{pg})$ and period $4 .^{d} 937512$ (Samus' et al., 2011).

The variability of the star was found by Miller (1965), using the moments of brightness on 88 photographic plates, it has defined elements of light variation and has noted, that the period of cepheid quickly changes. The star was thoroughly investigated by L. Berdnikov (1987, 1992), L. Berdnikov et al. (2019), as the cepheid that crosses the instability strip for the first time. It was reported as a Cepheid with Li over-abundance by Luck \& Lambert (2011).

\section{Observations}

The photometric CCD observations of V1033 Cyg were obtained at the Astronomical station near Odesa during the observation seasons in 2013-15 years, in V filter, later on, in 2017 year the observations were 
performed in $\mathrm{V}$ and $\mathrm{R}$ filters. We were using the $48 \mathrm{~cm}$ reflector AZT-3 of Astronomical observatory of Odesa National University, equipped with CCD photometer and Peltier cooler (Sony optical sensor ICX429ALL, $\sim 600 \times 800$ pixels) in the f/4.5 Newtonian focus (Udovichenko, 2012).

The datasets consists of $1864 \mathrm{~V}$-band and $713 \mathrm{R}$ band data points obtained from over 60 nights of observations. Two stars were chosen as comparison and check stars as close as possible in B-V color to variable. Comparison star is USNO-A 1200-14402731, $B_{\text {comp }}=14 .^{m} 285, V_{\text {comp }}=13 .^{m} 399$ (APASS, 2010), $R_{\text {comp }}=12 .^{m} 800$ (NOMAD, 2005); check star is USNO-A 1200-14401158).

The standard reduction of the CCD frames were carried out by using the MUNIPACK (Motl, http://sourceforge.net/projects/c-munipack) software. The procedures for an aperture photometry is composed of the dark-level and flat-field corrections, determination of the instrumental magnitudes and precision. The photometry was transformed to the standard VRc Johnson-Cousins system by means of the differential photometry method (Benson 1998). The transformation coefficient was determined from observations of standard stars (Udovichenko 2012). The finding chart with market-out variable, comparison and check stars is shown in Fig. 1. The errors in individual data points vary from $0^{m} .005$ to $0^{m} .02$.

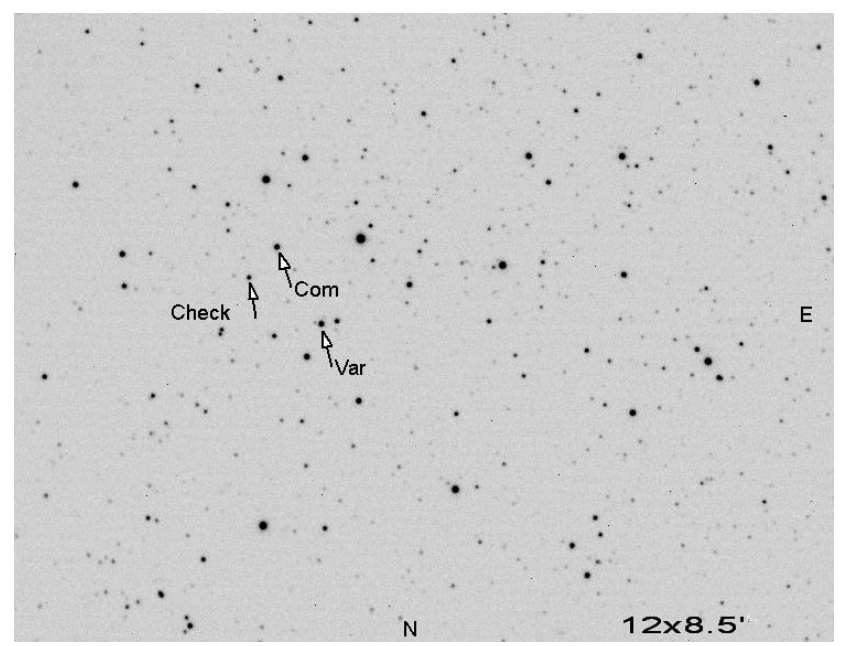

Figure 1: The finding chart V1033 Cyg with the comparison and check stars marked.

\section{Results}

Period. Using only the photoelectric moments of maximum from paper by Berdnikov et al (2019), current quadratic light elements of V1033 Cyg are obtained:

$$
\begin{aligned}
& \text { MaxHJD }=2452701.6164+4.9494727 \mathrm{E}+ \\
& +0.1423710^{-5} \mathrm{E}^{2}
\end{aligned}
$$

the phases calculated for these elements are given in Table 1. The phase curve V1033 Cyg from our observations and quadratic light elements is presented in Fig. 2.

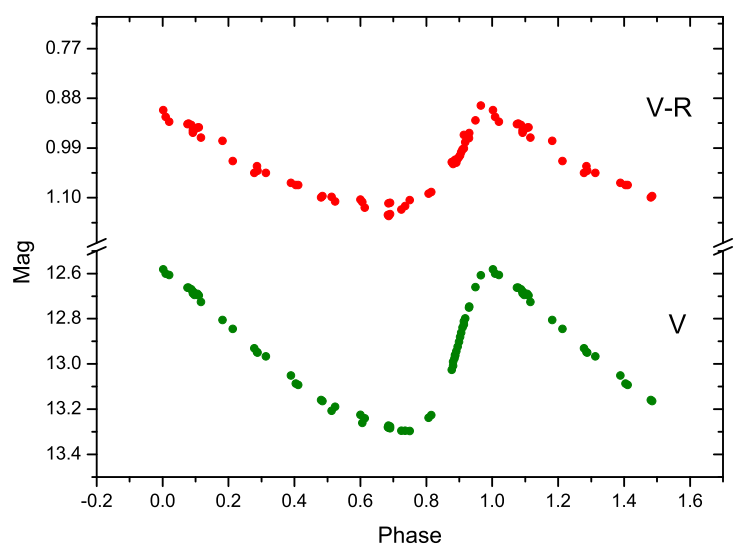

Figure 2: The phase curve in V-band and V-R color variations V1033 Cyg with quadratic light elements.

The $\mathrm{O}-\mathrm{C}$ diagram covering more than 100 years indicates a rapid increase of the period of $18.2 \mathrm{~s} / \mathrm{yr}$, in agreement with a first crossing of the instability strip for this star (Berdnikov et al. 2019).

Amplitude. The Fourier decomposition was applied to Berdnikov's photoelectric and our CCD observations of V1033 Cyg. For the V-amplitude obtained values $\mathrm{A}_{\mathrm{V}}=0.724 \mathrm{mag}$ (Berdnikov) and $\mathrm{A}_{\mathrm{V}}=0.718 \mathrm{mag}$ (our observations). Thus, there are no rapid evolutionary changes in the amplitude of V1033 Cyg.

Temperature. Using the $T_{\text {eff }}$ vs $(\mathrm{B}-\mathrm{V})$ calibrations from the papers by Kovtyukh (2007) and Kovtyukh et al (2008), effective temperatures $\left(T_{\text {eff }}\right)$ for the Cepheid were obtained, its are shown in Fig. 3. The average effective temperature for V1033 Cyg is $\left\langle T_{\text {eff }}\right\rangle=$ $5864 \pm 45 \mathrm{~K}$ (phases $=0.288$ and 0.846 ).

Hertzsprung-Russell diagram. The absolute magnitude $\mathrm{M}_{\mathrm{V}}=-3.13$ is found using the "absolute magnitude-pulsational period" relation of Gieren et al. (1998). The loci of V1033 Cyg on the H-R diagram are shown in Fig. 4. Evolutionary tracks from Salasnich et al (2000) for $\mathrm{Z}=0.019$ and $[\alpha / \mathrm{Fe}]=0$ are shown for reference. These models do not develop long blue loops for stars with $2-5 \mathrm{M}_{\odot}$, and hence they do not cross the instability strip. On the other hand, stars with 5-7 $\mathrm{M}_{\odot}$ do show blue loops that cross the lower part of the cepheid instability strip.

In Figure 4 also shown the location of yellow 
Table 1: V1033 Cyg. Observational list.

\begin{tabular}{|c|c|c|c|c|c|c|c|c|c|c|c|}
\hline $\begin{array}{c}\text { JDhel } \\
2450000+\end{array}$ & phase & $\begin{array}{c}V \\
\text { mag }\end{array}$ & $\begin{array}{c}V-R \\
\text { mag }\end{array}$ & $\begin{array}{c}\text { JDhel } \\
2450000+\end{array}$ & phase & $\begin{array}{c}V \\
\text { mag }\end{array}$ & $\begin{array}{c}V-R \\
\text { mag }\end{array}$ & $\begin{array}{c}\text { JDhel } \\
2450000+\end{array}$ & phase & $\begin{array}{c}V \\
\text { mag }\end{array}$ & $\begin{array}{c}V-R \\
\text { mag }\end{array}$ \\
\hline 8335.4033 & 0.887 & 12.960 & 1.019 & 8341.3018 & 0.079 & 12.662 & 0.936 & 8365.3242 & 0.929 & 12.751 & 0.968 \\
\hline 8335.4219 & 0.891 & 12.943 & 1.022 & 8342.3057 & 0.281 & 12.962 & 1.054 & 8365.4268 & 0.949 & 12.660 & 0.929 \\
\hline 8335.4395 & 0.895 & 12.923 & 1.014 & 8342.3271 & 0.285 & 12.964 & 1.059 & 8366.2520 & 0.116 & 12.726 & 0.967 \\
\hline 8335.4580 & 0.899 & 12.902 & 1.010 & 8343.2939 & 0.481 & 13.159 & 1.099 & 8374.2744 & 0.736 & 13.295 & 1.118 \\
\hline 8335.4766 & 0.902 & 12.880 & 1.006 & 8343.3164 & 0.485 & 13.164 & 1.096 & 8375.2354 & 0.930 & 12.746 & 0.957 \\
\hline 8335.4941 & 0.906 & 12.861 & 0.999 & 8344.3057 & 0.685 & 13.273 & 1.112 & 8379.2949 & 0.750 & 13.296 & 1.105 \\
\hline 8335.5137 & 0.910 & 12.839 & 0.993 & 8344.3281 & 0.690 & 13.276 & 1.111 & 8380.3623 & 0.965 & 12.608 & 0.896 \\
\hline 8335.5332 & 0.914 & 12.826 & 0.991 & 8345.2754 & 0.881 & 12.990 & 1.020 & 8381.4365 & 0.182 & 12.805 & 0.974 \\
\hline 8335.5527 & 0.918 & 12.798 & 0.977 & 8345.2939 & 0.885 & 12.976 & 1.019 & 8382.4619 & 0.389 & 13.051 & 1.067 \\
\hline 8336.4141 & 0.092 & 12.687 & 0.951 & 8345.3115 & 0.888 & 12.963 & 1.016 & 8383.5078 & 0.600 & 13.225 & 1.104 \\
\hline 8336.4287 & 0.095 & 12.685 & 0.947 & 8346.2979 & 0.087 & 12.669 & 0.939 & 8390.4492 & 0.002 & 12.581 & 0.906 \\
\hline 8336.4424 & 0.097 & 12.695 & 0.949 & 8346.3193 & 0.092 & 12.679 & 0.956 & 8397.3916 & 0.404 & 13.087 & 1.072 \\
\hline 8337.3340 & 0.278 & 12.930 & 1.045 & 8347.2793 & 0.286 & 12.947 & 1.030 & 8398.3965 & 0.606 & 13.260 & 1.109 \\
\hline 8337.3525 & 0.281 & 12.957 & 1.048 & 8347.2930 & 0.288 & 12.950 & 1.040 & 8399.3877 & 0.807 & 13.238 & 1.091 \\
\hline 8337.3701 & 0.285 & 12.953 & 1.035 & 8348.4072 & 0.513 & 13.207 & 1.098 & 8400.3916 & 0.009 & 12.601 & 0.921 \\
\hline 8339.3428 & 0.683 & 13.280 & 1.138 & 8351.3438 & 0.106 & 12.690 & 0.945 & 8401.4004 & 0.213 & 12.845 & 1.019 \\
\hline 8339.3604 & 0.686 & 13.282 & 1.140 & 8351.3623 & 0.110 & 12.697 & 0.944 & 8402.3809 & 0.411 & 13.092 & 1.072 \\
\hline 8339.3760 & 0.690 & 13.284 & 1.136 & 8362.2725 & 0.313 & 12.966 & 1.045 & 8403.3799 & 0.613 & 13.240 & 1.122 \\
\hline 8340.3037 & 0.877 & 13.026 & 1.021 & 8363.3115 & 0.523 & 13.189 & 1.108 & 8404.3818 & 0.815 & 13.226 & 1.087 \\
\hline 8340.3213 & 0.881 & 13.008 & 1.025 & 8364.3105 & 0.724 & 13.295 & 1.126 & 8405.3955 & 0.020 & 12.606 & 0.932 \\
\hline 8341.2842 & 0.075 & 12.662 & 0.937 & 8365.2510 & 0.914 & 12.811 & 0.961 & & & & \\
\hline
\end{tabular}

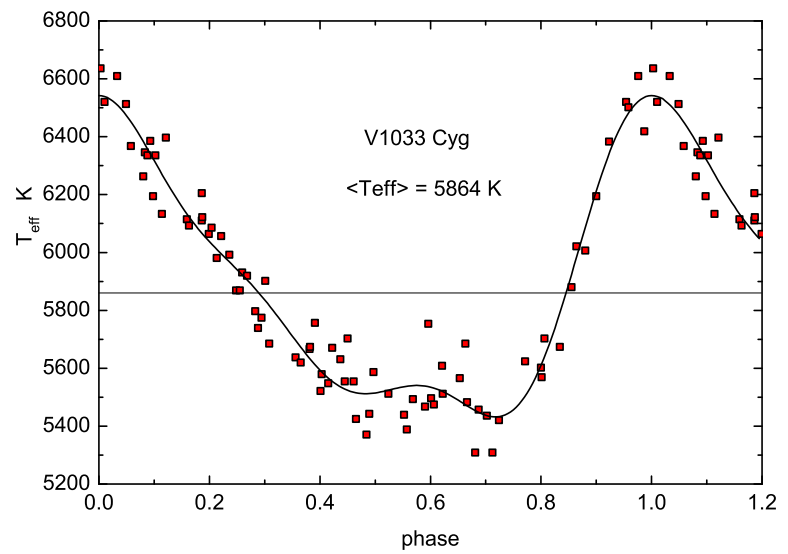

Figure 3: Variation of $T_{\text {eff }}$ of V1033 Cyg with phase.

supergiants and classical Cepheids in the H-R diagram (Kovtyukh et al 2010). First, we find that the $\mathrm{Z}=$ 0.019 tracks do a good job of predicting the positions of the blue loops and yellow supergiants for $\mathrm{M}_{\mathrm{V}}>-5$. The most luminous yellow supergiants in our sample have $\mathrm{M}_{\mathrm{V}} \sim-8$, consistent with the evolutionary tracks.

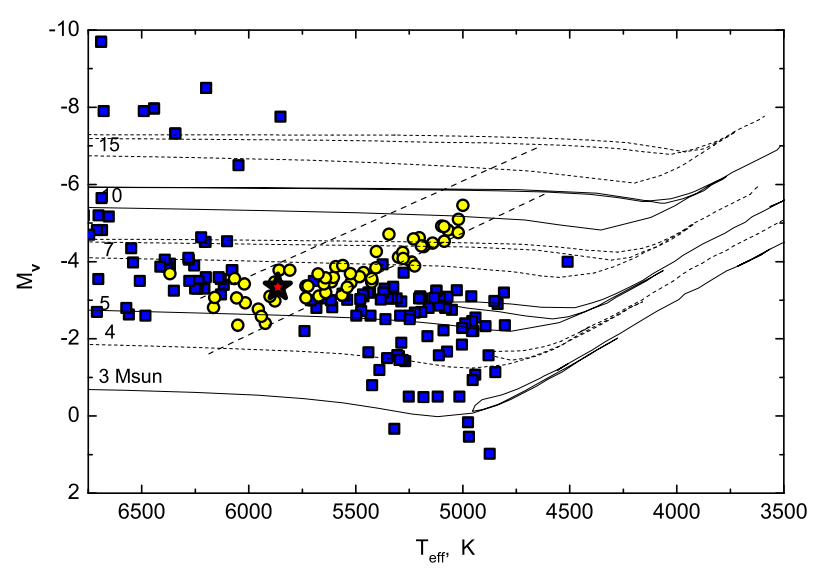

Figure 4: The H-R diagram constructed using our parameters. Classical Cepheids are plotted as open circles, supergiants as filled squares. Lines indicate evolutionary tracks by Salasnich et al (2000) for 15, 10, 7, 5, 4 , and $3 \mathrm{M}_{\odot}$ (top to bottom) for $\mathrm{z}=0.019$ and $[\alpha / \mathrm{Fe}]=0$. Dashed lines indicate IS for classical Cepheids. V1033 Cyg is shown as asteric. 


\section{Conclusion}

Our own analysis of V1033 Cyg, covering more than 100 years indicates a rapid increase of the period of $18.19 \pm 0.08 \mathrm{~s} / \mathrm{yr}$, in agreement with a first crossing of the instability strip for this star (this paper and Berdnikov et al 2019).

It was found that the $\mathrm{V}$-amplitude does not change rapidly. This is naturally explained by the position of the star in the center of the instability strip.

The results are consistent with fundamental mode pulsation in V1033 Cyg, as well as with a first crossing of the instability strip.

\section{References}

APASS, Star catalog: 2010, http://www.aavso.org. Benson P.J.: 1998, Intern. Amateur-Professional Photoel. Photom. Communic., 72, 42.

Berdnikov L.N.: 1987, Perem. Zvezdy, 22, 530.

Berdnikov L.N et al.: 2019, Astronomy Letters, 45, 4, 227.

Berdnikov L.N.: 1992, Astron. Astrophys. Trans., $2,1$.

Gieren W.P., Fouqué P., Gómez M.: 1998, ApJ, 496, 17.

Henden A.A.: 1996, Astron. J., 111, 902.
Kovtyukh V.V.: 2007, MNRAS, 378, 617.

Kovtyukh V.V., Soubiran C., Luck R.E., Turner D.G., Belik S.I., Andrievsky S.M., Chekhonadskikh F.A.: 2008, MNRAS, 389, 1336.

Kovtyukh V. V., Chekhonadskikh F. A., Luck R. E., Soubiran C., Yasinskaya M. P., Belik S. I.: 2010, MNRAS 408, 1568.

Luck R.E. \& Lambert D.L.: 2011, AJ, 142, 136.

Motl D.: 2009-17 http://sourceforge.net/projects/cmunipack

Salasnich B., Girardi L., Weiss A., Chiosi C.: 2000, $A \& A, \mathbf{3 6 1}, 1023$.

Samus N.N., Durlevich O.V., Kazarovets E.V., Kireeva N.N., Pastukhova E.N., Zharova A.V. et al.: 2011, General Catalogue of Variable Stars (GCVS database, Version 2011Jan).

Udovichenko S.N.: 2012, Odessa Astron. Publ., 25, 32.

Zacharias N. et al.: 2005, VizieR Online Data Catalog: NOMAD Catalog (Zacharias+2005), 1297. 